\title{
Effect of biomass burning over the western North Pacific Rim: wintertime maxima of anhydrosugars in ambient aerosols from Okinawa
}

\author{
C. Zhu et al.
}

Correspondence to: K. Kawamura (kawamura@lowtem.hokudai.ac.jp) 
1 This file includes "Section 1: positive matrix factorization (PMF) procedures" and Figures S1 2 and $\mathrm{S} 2$.

3

4 Section 1: positive matrix factorization (PMF) procedures

5 The data for the anhydrosugars (levoglucosan, mannosan and galactosan), primary

6 saccharides (xylose and trehalose), sugar alcohols (arabitol and mannitol) and water-soluble

7 inorganic ions $\left(\mathrm{K}^{+}, \mathrm{NH}_{4}{ }^{+}, \mathrm{SO}_{4}{ }^{2-}, \mathrm{Mg}^{2+}, \mathrm{Ca}^{2+}, \mathrm{Na}^{+}, \mathrm{Cl}^{-}\right.$and $\left.\mathrm{NO}_{3}{ }^{-}\right)$were subjected to $\mathrm{PMF}$

8 analysis to constrain the $\mathrm{K}^{+}$components using PMF 3.0. Based on replicate analyses,

9 uncertainties of $15 \%$ and $5 \%$ for the measurement of the organic compounds and ions,

10 respectively, were applied in the PMF analysis. The method detection limits (MDLs) of the

11 organic compounds were assigned using the analytical values as $0.0015-0.0081 \mathrm{ng} \mathrm{m}^{-3}$.

12 Similarly, MDLs of ions were assigned as $0.1 \mathrm{ng} \mathrm{m}^{-3}$. When the measured concentrations were

13 below the MDLs, 1/3 of the MDL was assigned to the data points and the corresponding

14 uncertainties were 5/6 of the MDL. The signal to noise values of different input components

15 ranged from 5.5-19.0. Based on a given understanding of the sources of the organic

16 compounds and ions, 3-7 factors were examined and 4 factors were determined. The minimal

17 robust and true Q values of the base run were 12103 and 21012, respectively. The

18 concentrations and percentages of the tracers in each factor of the bootstrap run were close to

19 those of the base run results. The $\mathrm{Q}$ values and factor profiles of the $\mathrm{F}_{\text {peak }}$ rotation runs showed

20 no significant changes compared to the base run, indicating stable PMF results. The obtained

21 PMF factor classification is shown in Figure $\mathrm{S} 2$, and the $\mathrm{K}^{+}$component allocation is shown in

22 Figure 5. 


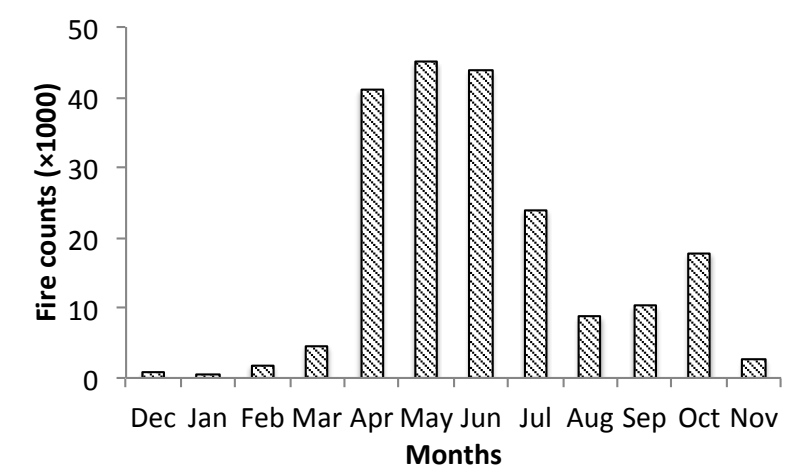

24 Figure S1. Fire counts in Middle to North Asia (MNA, 30-60 ${ }^{\circ} \mathrm{N}, 80-130^{\circ} \mathrm{E}$ ) in the months 25 from December 2009-November 2011. 


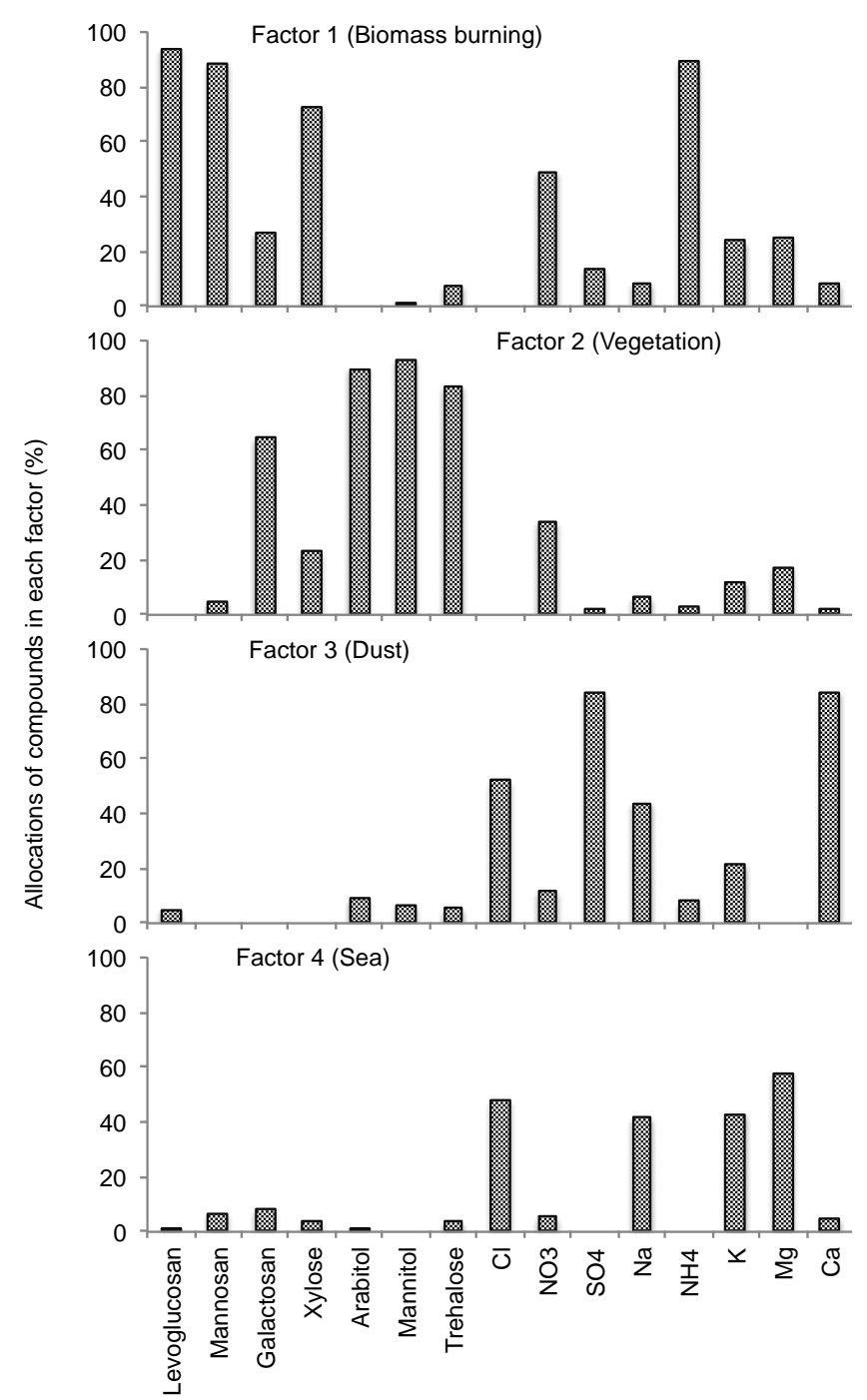

27 Figure S2. Factor classifications by positive matrix factorization (PMF) analysis at Cape 28 Hedo, Okinawa. 